(1)

GeORgE Fox

UNIVERSITY
Digital Commons @ George Fox University

2018

Teaching and Learning in Kenya: Examining the Shifts in Cultural Learning of Experienced Educators

Eloise Hockett

Follow this and additional works at: https://digitalcommons.georgefox.edu/soe_faculty

Part of the Teacher Education and Professional Development Commons 


\title{
Teaching and Learning in Kenya: Examining the Shifts in Cultural Learning of Experienced Educators
}

\author{
Eloise Hockett \\ School of Education, George Fox University, Newberg, OR, USA
}

\begin{abstract}
This qualitative case study examined the cultural learning insights of four educators during and after an immersion experience in Kenya. During this experience the participants delivered professional development sessions to teachers in two rural Kenyan schools, and stayed with Kenyan families. Mezirow's transformational learning theory, self-reflection, and cultural humility were utilized as a framework to examine the educators' learning experiences. Data were collected through pre-trip planning sessions, journals, debriefing sessions, field notes, and a 6-month follow-up interview. Results of the data produced five main themes: (1) general observations; (2) recognizing biases and assumptions; (3) cultural insights; (4) cultural humility; and (5) spiritual insights. Even though these participants had prior interactions with different cultures, this trip expanded their experiences and provided them with further understanding of how to interact with different cultures abroad, and within their professional contexts. While cultural aspects tend to be emphasized in undergraduate programs, these experienced educators benefitted from this cultural immersion experience, which could be used to make a case for continuing the same emphasis in graduate programs.
\end{abstract}

\section{Introduction}

The increasing migration of various populations to the United States continues to impact our preschool through twelfth-grade schools with diverse populations of students. All education preparation programs, especially those within Christian institutions, have a unique opportunity and responsibility to prepare our teacher candidates to love our neighbors within the biblical framework while also meeting the needs of all students in our nation's schools. Many higher education institutions promote service learning and international experiences for their undergraduate students across various disciplines to further knowledge and skills in working with diverse cultures. However, for institutions with graduate programs in teacher

CONTACT Eloise Hockett $\otimes$ ehockett@georgefox.edu $\mathrm{E}$ Co-Chair, School of Education, George Fox University, 414 N. Meridian St., Newberg, OR 97132, USA.

(C) 2018 Taylor \& Francis and Andrews University 
education, the needs of graduate students to further their cultural knowledge and understanding of diverse populations can be overlooked or even neglected.

\section{Purpose of the study}

Teacher educators at all levels across the nation are expected and often mandated to continue their learning about teaching pedagogy, curriculum, standards, and self-reflection in all areas of education. As teachers continue to develop their professional competencies and hone their pedagogical skills, it is important they also continue learning about effective teaching strategies related to cultural diversity. Working with different cultures and learning about diversity can take many different forms. Immersion experiences in other cultures and countries can provide the teacher educator with unique opportunities to build upon their knowledge and experience and apply the learning from those immersion experiences immediately into their classrooms and schools.

The purpose of this study was to immerse U.S. teacher educators into an African culture and expose these teacher educators to different views on culture and education through teaching professional development workshops in Kenya. According to Pusch (2009), this kind of effort is what global leaders need and helps to raise teachers as organizational leaders who train and develop our future leaders with a global mindset.

In order to assist teacher educators in the graduate programs at my university (George Fox University) examine their beliefs and perceptions about working with other cultures globally and locally, I arranged an international teaching and learning experience in Kenya. I sought to answer the research question: What were the key learning experiences of graduate level teacher educators after an educational immersion experience in Kenya?

\section{Review of the literature}

\section{Transformational learning theory and the adult learner}

This review of the literature explores the connections of Mezirow's transformational learning theory for adult learners with the sub-themes of selfreflection and cultural humility. Together, these themes provide a lens through which to examine one's learning in various contexts.

Since the participants for this study were adult learners, I utilized Mezirow's (1991; 1997) transformational learning theory primarily because of its rootedness in the principles of adult learning (andragogy). Knowles, Holton, and Swanson (1998) define the readiness of the adult learner as more developmentally and process-oriented with many life experiences that 
provide a rich foundation for learning and dialog. In pairing the principles of adult learning with Mezirow's $(1991$; 1997) theory, all persons have their own view of the world, which are based on preconceived biases and assumptions (Christie, Carey, Robertson, \& Grainger, 2015), and have been learned throughout life whether in formal schooling or through life experiences. Especially for adult learners, their worldviews are already deeply rooted and often difficult to change.

As learning takes place, the adult learner moves within a "frame of reference" (Mezirow, 1997, p. 5). These frames of reference contain three different aspects: "cognitive, conative, and emotional components" (p. 5) and are also centered within the dimensions of "habits of mind and a point of view" (Mezirow, 1997, p. 5). Transformational theory holds that as adult learners are faced with new situations, especially within the context of an unfamiliar situation or entity, prior assumptions and worldviews are challenged, and the adult learner is required to either ignore the new information or knowledge or move through the various frames of reference in order to come to new understandings and learning about the various contexts (Mezirow, 2012). Within Mezirow's (1991) theory, self-reflection becomes the key in addressing prior biases and assumptions in order to move toward transformation.

\section{Self-reflection and the adult learner}

Self-reflection, when paired with the principles of andragogy, allows for the adult learner to further assess personal motives, biases, and assumptions (Taylor, 2009). Osterman and Kottman (1993) write that the reflective process has a greater impact when the learner is invested in the process and there is also motivation to learn and change. Osterman and Kottman further state that true learning cannot take place without reflection and without the results of the learner's reflection leading to action. Reflective practice is essentially then a cyclical process that continues to adapt to changes and then looks back on the process, only to repeat the cycle once again (Larrivee, 2000). For adult learners, the cycle of reflective practices furthers relevancy, motivation, and meaning in their learning. However, as Mezirow (1991) notes, reflection is not just self-examination, but a focused critique with the intention to make changes. It is within this new knowledge that the learner has moved to the point of transforming their learning (Marmon, 2013). 


\section{Cultural humility and transformational theory}

Within the current educational environment in U.S. schools, teacher educators are expected to demonstrate cultural competency or sensitivity when working with the students in their classrooms. Higher education institutions preparing new teachers are required by state and national standards to prepare candidates and graduates who are able to meet the needs of all students upon completion of the preparation program. Learning about and working with other cultures requires a process of life-long learning at all levels. The concept of cultural humility furthers the building blocks of transformational theory by also addressing one's previously held biases and assumptions regarding culture and diversity.

Cultural humility, a construct originating in the medical field, promotes a holistic approach in working with those of other cultures (Fadiman, 1997; Ross, 2010; Tangney, 2000; Tervalon \& Murray-Garcia, 1998; Wear, 2008). Cultural humility helps move the learner beyond mere proficiencies or competencies, and it places the learner in the role of a lifelong learner regarding culture and interactions with those who are different than the learner. The framework of cultural humility also redefines the way we think and interact with those of another culture, leading to more respectful interactions and a better understanding of more appropriate and relevant ways to meet the needs of those with whom we work (Hockett, Samek, \& Headley, 2013; Fadiman, 1997). Cultural humility is also deeply rooted within the biblical principle of humility found in Philippians 2:3: in humility count others more significant than yourselves.

The main tenets of cultural humility are formulated around the following core themes:

- Building relationships is first and foundational with intentional and focused listening.

- Intentional listening: gathering information; listening to the needs of the people.

- Setting aside pre-determined biases and assumptions and critically examining those in light of new information and knowledge.

- Collaboration and co-learning; learning with and from one another (Hockett \& Muhanji, 2017).

\section{Implications for this research study}

Mezirow's $(1991,1997)$ theory of transformational learning provides a wellused and reliable framework for examining a person's change or shift in 
ideas and thought processes. Researching shifts in cultural understanding and interactions are especially helpful and necessary for educators in all disciplines in preparing to work with all populations. Self-reflection and cultural humility provide both breadth and depth of additional self-examination and cultural preparation to help further prepare teachers at all levels for the diversity of the students they will encounter anywhere they are called to teach.

\section{Methodology}

This qualitative case study focused on the learning experiences of four educators during a 2-week teaching and learning immersion service trip to rural Kenya. I collected data via the following methods: (1) trip applications and essays; (2) observations and field notes during trip planning and preparations; (3) personal and group interviews during the trip and six months later; (4) participant journals, and, (5) photos. The results of the data collection helped to answer the following research question: What were the key learning experiences of graduate level teacher educators after an educational immersion experience in Kenya?

\section{Participants}

The participants for this study were four educators with a variety of experiences, ranging from K-12 teaching and substitute teaching to university teaching in a nursing program. There were three female and one male educator (respectively referred to herein as Diane, Julie, Gloria, and Andrew). Three were enrolled in graduate education programs in the George Fox University College of Education, and the other was a veteran teacher and alumnus from the George Fox University graduate teacher education program. Although three of the four educators were enrolled in my graduate courses and thus a convenience sample, all completed an extensive application process for the trip to Kenya before their participation was approved. According to the self-reporting on the application, all four of the participants viewed themselves as culturally competent and able to effectively relate to people from other cultures.

Diane was a nurse by training, and enrolled in our educational doctoral program. She had many years of nursing practice in addition to more than six years as a nurse educator. She had lived in other developing countries while her husband worked in the development field. Diane considered herself very adaptable in any kind of situation because she had lived overseas. Her family had also adopted an indigenous child while living abroad in a South American country. Her purpose for going on this trip was to further 
her knowledge of African countries and their type of nursing care, as well as to explore nursing and education partnerships in Kenya for undergraduate nursing students. She had already been to another African country on a prior nursing-related missions trip.

Julie was enrolled in the Master of Education program. She had been a substitute teacher in elementary classrooms for more than 20 years. Julie had not been overseas to a developing country but had worked in U.S. schools with a high percentage of poverty (free and reduced lunch) and English Language Learning (ELL) populations. She was confident in her skills in working with children from these backgrounds. Julie chose to go on this trip to expand her experiences educationally and move beyond her personal comfort zone. She also affirmed she felt God called her to go on this trip.

Andrew had been an elementary classroom teacher for more than 15 years. Since graduation from college with his teaching degree, he had worked in the same low-income school district. His work with diverse populations was well respected in his school district, and he had a well-earned rapport with the parents/guardians of his students. Andrew chose to go on this trip to gain more information about education in Kenya, use his teaching skills and knowledge to benefit others, observe how other nonprofit ministries operate in developing countries, and make new friends. Andrew's only previous overseas experience was to Europe during his college years.

Gloria had been a middle and high school teacher for over 15 years and was enrolled in the Master of Education program at George Fox University. Gloria had extensive travel experiences, primarily in European countries. Although Gloria did not teach in a school district that was very diverse, she considered herself culturally competent because of her travel experiences and friendships with people from other countries. Gloria's interest in this trip was to further her educational experiences on a different continent and to learn more about another culture immersed in their setting. As Gloria was preparing her application, she stated: "I feel called to go on this trip."

\section{Procedures}

The purpose of this trip was to offer an international immersion trip that combined mission and service components to education graduate students from a private Christian institution in order to further their knowledge and skills with diverse populations. During the two week experience, the team of U.S. based educators were immersed in Kenyan cultural as we taught professional development sessions to teachers at two different schools in 
different locations, and stayed in the homes of villagers during the first part of the trip.

\section{Trip preparations}

One significant part of the data collection process involved the trip preparations. Prior to the trip, I conducted four 3-hour required preparation sessions for the participants. I drew on my extensive background and frequent trips with ongoing work in Kenya to determine what kind of preparation would be most useful for these educators. I intentionally structured our planning sessions to address the main cultural aspects we would encounter, as well as to prepare the group for the planned events while in Kenya, and how to respond to any unplanned events. During these sessions I also took careful notes of comments and discussions that would also inform this research project.

Each participant was required to read at least the following resources:

- The Last Hunger Season: A Year in an African Farm Community on the Brink of Change (Thurow, 2012).

- Cross-Cultural Servanthood: Serving the World in Christlike Humility (Elmer, 2006).

- Cultural Humility: A Framework for Local and Global Engagement (Hockett et al., 2013).

I selected each of these sources because they provided vital background information on general cultural issues, cultural practices of Kenya, and biblical principles for effective cross-cultural interactions. Further, I believed these resources would best prepare the participants for the overall trip experience.

\section{Teaching preparations}

For this trip, our team had been invited to provide professional development sessions to teachers from primary schools in two different locations in western Kenya. The first school I had previously visited a number of times and developed key relationships with the leaders of the school and community. The school leadership had provided suggested topics they believed would be of most value to their staff. We then chose those topics that best fit the knowledge, expertise, and experiences of our team members. I was also knowledgeable about the basic culture of the region and educational system of the country so I could provide the background information necessary for the work we would do at each school. 
As a part of the teaching preparation we developed a basic schedule for our teaching days. We allowed space for opening introductory remarks at the start of each day, tea breaks, lunch, and end-of-the-day group debriefing sessions. As we developed the overall schedule, we set the structure so that I, as team leader, would teach the first introductory sessions, and then allow the other team members to team-teach and plan the remaining sessions. While others were teaching, the rest of the team would interact and participate with the Kenyan teachers and leaders. The rationale for this strategy was to help the team acclimate to the type of teaching, pacing, and interactions that would be culturally appropriate. At one point during the planning sessions, Julie suggested, "Let's just take out the opening part so that we have more time for our teaching." This statement provided a key opportunity to explain the importance of the Kenyans' cultural practice of welcoming visitors, introducing the event, and setting the stage for the work to come. It was also important for the team to be reminded that we were guests in another culture and needed to be sensitive first to the Kenyans' practices and procedures and not to assert our own agenda (Elmer, 2006).

During our preparation for planning, we also discussed culturally appropriate teaching strategies and materials we would share with the Kenyan participants. The objectives for this part of our planning were to provide the Kenyan teachers with ideas and strategies they could implement into their teaching, while still keeping within their required national curriculum goals and timelines. Since we did not have much information about the second school, we decided to keep the same lessons and structure, and then adapt as needed once we arrived at the other school and consulted with the school personnel. That way we did not have to prepare separate lessons, but could adjust and adapt as necessary in order to meet the needs of the second school.

\section{Cultural preparations}

Our cultural preparations were intentionally focused and planned, including the topics of food, basic customs, transportation, and language. During the day at our teaching sites, we would be in a professional setting with English as the language used for instruction. Potential language barriers were already reduced, which eased the stress of possible communication issues in our teaching and interactions. Through our home stays with families in the village, we were still able to communicate at the basic levels with many people and further our goals of building the relationships with the people.

Our cultural preparations also covered the various differences between the individualistic culture of the United States and collective culture of 
Africa (Nwosu, 2009), and how these differences would inform and affect our teaching and interactions with the Kenyans. An example in this category pertains to how the Africans view the concept of time. Events often take longer then planned, and delays are typical for many reasons. The Kenyans are very relational oriented, which means building relationships with people has more importance than beginning a meeting on time (Nwosu, 2009). As an example, it was important for the team members to understand that our waiting for the beginning of a teaching session was more than likely related to a cultural procedure or interaction of which they may not be aware.

\section{Spiritual preparations}

Finally, spiritual preparations were carefully integrated into our sessions. All participants on this team identified as Christian and were aware that this project was also a missions/service trip that incorporated an educational focus. The regions in Kenya where we were doing our work had a high population of those who would call themselves Christian and practice traditional Christian customs. For example, our teaching sessions in Kenya began with praise and worship, prayers were said before meals, and prayers were spoken at the end of the day as we departed for the homes.

I also cautioned the group on topics that might not be appropriate for the setting where we would be working. Since the Kenyan Christians overall tend to be more conservative, more controversial topics would need to be discussed with care, or avoided altogether. Our ultimate goal was to show great respect for the Kenyans' views and cultural traditions surrounding those views. However, no matter how careful we were, we were not always successful in avoiding a cultural misstep.

As a part of the spiritual preparations we built the foundation of our work on the various biblical principles of how to treat one another with God's love and kindness. We used the passage from Philippians 2:7 to discuss what it meant to serve others from any culture, within the framework of humility. Cultural humility, as described in the review of the literature, puts each one of us in the role of the learner, listening to gain understanding (Elmer, 2006). For the Christian especially involved in a cross-cultural ministry or other efforts, this concept is vital to building strong and ongoing relationships.

\section{Additional data collection methods}

\section{Trip application and essays}

Prior to acceptance on this trip, the team members submitted essays that indicated their interest, qualifications, and reasons why they wanted to 
participate in this kind of a cross-cultural experience. This information was valuable for me as team leader in understanding the motives and goals for each person in order to help them make the most of their experiences while in Kenya.

\section{Debriefing sessions}

During the trip we held debriefing sessions as a group at the end of the teaching days and at the end of the trip while still in Kenya. Each session began with the key question: What was your main insight or learning experience for today? From this question I then utilized the interview protocol of following up on the answers of the participants and asking clarifying questions in order to gain more understanding (Berg, 2012).

Six months later I individually interviewed each team member to determine what additional reflections had emerged since we had arrived back in the United States. Each session began with the initial questions: (1) What events or experiences are you still processing? (2) What takeaways from the trip will you put into practice in your classroom or school? I then followed the interview protocol of asking follow-up questions leading to deeper questions (Berg, 2012) All of these sessions were transcribed, coded, and examined for common themes according to qualitative research protocols (Leech \& Onwuegbuzie, 2008).

\section{Participant journals}

Team members kept journals during the trip with the intent to assist in processing their learning and experiences. At the end of the trip the team members made copies of their journals for the purposes of this research project. Each journal was carefully examined for specific insights unique to each team member, as well common themes and trends (Leech \& Onwuegbuzie, 2008).

\section{Field notes}

Throughout the entire trip, I made note of observations and conversations between my team members and the Kenyans during teaching situations and in the social settings. These notes were valuable in helping the team process cultural interactions, as well as specific events they encountered. For example, Andrew had explained to one Kenyan man that he and his wife had only one child due to infertility issues. The Kenyan man replied: "I will pray you can find another wife who will provide you with more children." The Kenyan man's comment was completely unexpected to Andrew, and also provided a significant cultural learning opportunity for the entire team. Even though I have knowledge of basic Kenyan culture, 
this example provided more insight into the beliefs of the tribal group we were working with. We shared this example with our Kenyan hosts who then explained more in-depth the customs of that local area.

\section{Findings}

In this section I report on the main themes from the data analysis to answer the research question: What were the key learning experiences of teacher educators after an educational immersion experience in Kenya? I carefully followed the protocols for qualitative research as described by Creswell (2013) and Leech and Onwuegbuzie (2008). I first transcribed all of the recordings from the debriefing sessions and the follow-up interviews. As I read through all of the narratives, I made notes and looked for common ideas, then organized those ideas into main themes and sub-themes. Next I examined the remaining data I had collected and examined all of the data together in order to justify the themes (Creswell, 2014). In this way I could determine the main themes from all of the data to ultimately answer the research question.

\section{Theme 1: General observations}

One of the first themes to emerge was related to general observations. Since none of the participants had previously been to Kenya and only one to another country in Africa, each person was first attentive to the general surroundings and environment. Some of those observations included: the unpaved roads; women walking carrying water and other loads; children in uniforms walking in droves to and from school along the roads; the lush green areas near the rivers; the vast corn fields; and the various types of housing along the roads and in the villages. Gloria demonstrated this attentiveness to surroundings at one of the school sites when she eagerly asked: "What are all those cute little buildings?" She was immediately embarrassed when she was told those were latrines for the students! However, that experience helped her to watch and observe more intently and ask different kinds of questions later as we progressed through the our trip.

Andrew's observation about the Kenyan roads also helped his understanding of why people might often be late to events. He noted:

realizing that if there's rain, it would be clay roads, it makes them very slippery. Or if you try to drive down the road at any substantial speed, with huge holes and huge bumps in the road... Most people don't drive cars.

This insight was even more profound for the entire team one day at the end of a teaching session when a torrential rainstorm blew through the area. We had to stop our teaching because the rains were so loud on the 
tin roofs that no one could hear a conversation. Everyone, students included, took cover in places throughout the school wherever possible in order to avoid the wind and rain. For the entire team, this event was an insight into how even daily occurrences such as rainstorms hinder or even entirely stop the educational process. We later discovered that when a storm is approaching the area, the teachers often send the students home for the rest of the day so that they can be home safely before the heavy rains and darkness set in, thus further disrupting the educational process.

\section{Theme 2: Recognizing biases and assumptions}

Each participant experienced significant learning in the areas of prior biases and assumptions. Diane made one of the first observations related to assumptions of western influences in Kenya as she reflected in one of our debriefing sessions:

Professionally, even though I had been warned, I guess I didn't believe, how sheltered they [the Kenyans] are from western influence. I really didn't. I assumed that they had seen white people on television... but I have been very shocked at how little western influence the villagers do have in fact.

Diane's initial revelation began with assumptions of the villagers' access to electricity, television, or other media. When Diane realized the villagers had extremely limited access to any of these resources, she quickly adjusted her teaching lessons as she worked through her incorrect assumptions.

Andrew also had made an assumption about the Kenyan's limited access to various resources. He was shocked to discover that one of the geography teachers had never seen a photo of the Grand Canyon, yet taught about the Grand Canyon. Andrew had assumed that the teacher would be able to go to the internet and download whatever resource was needed. The entire team learned a valuable lesson when they discovered that most of the teachers in the village where we were working had no internet access unless they traveled to an internet cafe and paid fees for their services. Most of the teachers did not have the extra funds for such an extravagance.

Another assumption was related to the schools themselves. Julie was surprised at the large number of students who attended even a village school and how long a Kenyan student's day was compared with the typical American school. She had been expecting the school day and situation to be similar to what she was used to in the states and was surprised they would be in school so long each day, usually from 8 AM-4:30 PM. She stated: "Our team quickly had to adjust to how time was used in Kenya. The Kenya view of time impacted our lessons and how we planned our day."

Andrew reflected in one of our debriefing sessions: 
I think my 'ah-ha' moment [moment of sudden insight] was I heard about Kenyan time, but I had not lived Kenyan time, and so I am a person that's very organized with my time, and on time for everything. Coming into the area and at first seeing people not show up at the scheduled time was something that I first had to recognize that it was happening and to show patience before just jumping to conclusions.

Even though in our trip preparations we had discussed the concept of time in Kenya compared with a western view of time, it was an adjustment for each of the team members to experience the concept throughout the trip. The team continued to learn that time in Kenya was viewed differently, in that, relationships came first and often would interrupt previous schedules. The tensions within the concept of time came when travel schedules and school schedules were adhered to, but other events may be delayed for a variety of reasons. During one of our teaching sessions at the first school, the principal was delayed by a required meeting called by the regional education office, thus delaying the start of our session. According to cultural norms, we could not begin without the principal in attendance. This occurrence was another valuable insight for the team members.

\section{Theme 3: Cultural insights}

As we progressed through our time in Kenya, it was evident that each person was moving beyond initial cultural assumptions and recognizing opportunities to shift their thinking and perceptions. While some of the lessons were more obvious than others, each participant had a significant learning experience in the area of cultural issues. Diane explained how she had to address one of her biggest assumptions about previous life experiences in relation to cultural issues. "I thought my filter was pretty good having traveled a bit and seeing and living in different cultures. But in thinking more deeply about cultural competence and cultural humility as I have been challenged to do on this trip it has made a huge difference." As we reflected on this insight, Diane admitted this trip was the first time she was forced to reflect on her cultural proficiency, and she had to address some prideful assumptions in this area. She went on to state:

And I realized that I had a lot of those 'ah-ha' moments there. That I was really at the point in my life, my education, my personal spiritual journey, but there were a lot of ah-ha moments where I moved along with certain assumptions, but slowly, but slowly I recognized that I needed to stop and check assumptions and listen to what was going on and observe more what was going on around me in order to get the true picture as close to what was really happening.

In another example of cultural insights, Gloria experienced a major faux pas in one of her teaching sessions at the first school site. During an illustration for a writing lesson, Gloria had used an example that women would 
not want to have arranged marriages, but instead choose their own husband. It was the first thing that had come to her mind and she admitted later she had been thinking through her own American lens. During the next break in the teaching session we took her aside and quickly pointed that arranged marriages still occur in Kenya, especially in the rural areas. Gloria felt embarrassed with her cultural mistake, especially since she had made another assumption about the culture. However, we agreed she would take a proactive approach and apologize to the teachers for her error. The participants were very gracious, forgiving, and laughed with Gloria as she explained she was trying to be a good learner as well. They had not been offended by her remarks, and the incident allowed for lively and interesting conversations on both sides about cultural practices. Our transparency in this case led to more relational building with the participants.

At the second school site we visited, Diane wrestled with a cultural aspect related to her teaching. As Diane taught a lesson on health, she soon recognized how strong the tribal influences were over certain health practices. In this particular example, the teachers from the local tribe believed that babies born in the eighth month were more likely to survive than babies born at full term. When Diane presented the teachers with factual information to the contrary, she was quite surprised they did not shift their views even with this new knowledge about childbirth and infant mortality rates. Diane assumed that the teachers would automatically listen to her since after all she was a nurse professional from the United States. This experience altered her previous assumption that surely a trained person would be believed over an untrained person. Throughout the trip and afterward Diane continued to wrestle with the teachers' responses and struggled to know how to make meaning of this revelation. Just because an educated American said something was true, it did not mean the local people would take it as such. In this instance, many cultural and tribal implications prohibited such a quick a change of thinking from the Kenyans.

The realization of actual poverty was one that most of the participants were not prepared for, even though we had discussed the topic in our pretrip sessions. Only Diane had previously been to another African country and lived in Brazil for a time, yet she still wrestled with issues of poverty in Kenya. Diane shared the following thoughts:

to be in Janerose's home; now I don't know if in her little village she would be classified as one of poverty because she had a husband that worked, she had one college educated daughter... But from my vantage point, from my assumptions, if you don't have a toilet in the house or if your kitchen is out in the back there and you have to go to the well to get your water every time, there is some form of poverty. But, that house was really full of love. Oh my goodness, Janerose just loved, loved, and so all that stuff about poverty did not make sense. It just did not make 
sense. You have to rethink the whole thing, and you just can't do it in a week. You have to roll up your sleeves and do it.

As Diane later reflected, there were no easy answers to the issue of poverty and it was going to take more conversations and study to find answers.

Prior to the trip Julie assumed she knew what poverty was all about. During one of our preparation meetings, she had remarked: "Poverty is poverty no matter where you are." Once we were in Kenya, only then did Julie realize that poverty was indeed different than what she was used to in an urban school district. The house were she stayed in the village had a kitchen out back, a latrine, and a well on the property. However, just a few houses down the road the children had to go fetch water from a stream, they had to go collect the firewood, the kitchen was a mud hut, fuel for a fire to cook food was limited, and food sources were scarce due to the time period between one harvest and the next, and the people were continually exposed to some diseases to which we are not exposed in the United States. Julie also soon recognized that social service agencies were not available to meet the needs of people. Mere survival was a daily struggle for many in this region.

In another example related to culture learning, Julie had one of the more profound insights of the participants. As she explains:

We were traveling in the car and I asked [our Kenyan driver] what the Africans refer to themselves as, whether it is Kenyans or African-Americans or African, even though they are not African American, which I knew, but yet all black children in America I have referred to as African American. That was a huge 'ah-ha' moment for me, I mean I am 50 years old and all of my life every black person has been an African American, and that is so not true.

As we debriefed this interaction many times, Julie was appalled at her lack of cultural understanding through the years, and recognized steps she could take in her own classroom teaching to implement this new knowledge and honor the cultures with which she works.

\section{Theme 4: Cultural humility}

Each participant experienced several insights related to various aspects of cultural humility, but in different ways. Andrew reflected on his experience with humility during one of our debrief sessions:

My first experience in the village was that it all started with relationships and respecting another one's culture, and out of that respect and relationship grew trust. And out of the growth of all of that, came this beautiful understanding and friendship and so everything was built upon getting to 
know each other before just coming up with what somebody needs and pushing something on someone else.

In this preceding example, Andrew noted that relationships and respect were very key in the work we were doing with the teachers. Without this level of respect, our work most likely would have been meaningless for both sides.

Gloria had another "ah-ha" insight related to cultural humility as she visited with the deputy school principal about the daily school schedule:

I realized that their daily schedules were 30 -minute periods, punctuated by a break, a lunch, a break for games... I thought, that is a big problem when you only have face time with your students for such a short amount of time... how can you get to the deeper level rather than just the concrete level... I found myself thinking, well this is a problem, and my 'ah-ha' moment was when I realized if we just adjusted their schedule and took away their teatime, according to westerners' thinking that would be awesome because they would have more face time. But teatime is important to their culture, and it was an ah-ha moment that I should not take away something I am finding very beautiful about their culture and replace it with things.

As we unpacked this revelation during one of our debrief sessions, Gloria utilized the framework of cultural humility to recognize the beauty of the Kenyan culture and how our western view of solving the school scheduling would be dishonoring to the Kenyan culture.

In the post-trip follow-up interview, Andrew shared another perspective of cultural humility that made an impact on him. He stated:

The important things such as cultural humility and talking to us about some of the expectations for how we could come into a community and be the least offensive as possible, I think that really prepares us to make more of an impact for the Lord if we can come in without shutting people down in some conversation because we have offended them in some way that isn't even intentional.

Through this example, Andrew realized how attitudes and actions could hinder any spiritual efforts as we worked in the village.

Both Gloria and Andrew wrestled with the aspect of cultural humility and how best to help people. Through our trip preparations and interactions with the Kenyans in the village, both reconsidered some of their previous assumptions about helping others in need. Andrew stated:

I think I reached a different level of culture and how to help people. I think that for many years I recognized the importance of cultural understanding, and to recognize the importance of how our cultures are different, and not just pushing my culture onto someone else's culture, but I really felt I was pushed to a new level when I was in Kenya, about not just helping out the needs from my perspective, but helping them to help themselves, and the people coming up with the questions they think they need help with; them coming up with the answers they need help with. And not 
because I have the money or I have the resources and being in control of what you need.

In this example Andrew was wrestling with the western perspective of how to help, and found that the approach of cultural humility was more honoring to the culture.

Gloria had a similar shift in her thinking about the best way to help or find solutions to the many needs. She reflected:

It is very difficult for me not to give gifts of money to people who have been generous with their financial stuff to me, and I had to exercise a lot of restraint, and I failed in some instances. But my idea is that they don't have much and they are sharing and I have more, and I want to contribute and so I had to take your advice (speaking to the author) and really hold back and it was really challenging for me.

In this particular example, Gloria wanted to give one of the teachers money to assist with a needy student he had taken into his home. In order to help her understand the differences between a common American view of helping and a Kenyan perspective, we had a conversation with our Kenyan ministry partner and his wife. Using questioning strategies, they helped Gloria to see that the needs are many, and if you help one, then you also need to help others. Discerning the level of giving is complicated and must be handled with care (Corbett \& Fikkert, 2009).

\section{Theme 5: Spiritual insights}

Even though this trip to Kenya was primarily an academic focus, coupled with mission and service components, the participants were not necessarily expecting to be moved by the spiritual lessons that occurred. As we prepared for the entire trip, including the academic lessons, everything was framed around the Fruits of the Spirit from Galatians 5: 22-23: But the fruit of the spirit is love, joy, peace, patience, kindness, goodness, faithfulness, gentleness, and self-control. Our goal was to infuse these traits into the workshop lessons, as well as into our actions and interactions while in Kenya. Gloria reflected on how this emphasis continued to shape her during and after the trip:

I was never introduced to the 'fruits of the spirit.' Being raised Catholic I did not have a belief knowledge base-the priests and the popes read the Bible, and everyday people don't-... I did not know what to call it. It definitely gives a meaning and words that we can say out loud, things that we actually do show kindness and joy to my students and the people around me, love and respect... Just the act of praying every day I think has improved my practice; it has trickled down. It is funny, I gave lessons that were very much curriculum driven, with practical tips of carrying them out, but I think the way more important lessons were with the fruits of the spirit. 
Diane talked about her spiritual discoveries from another perspective: "And I realized that while we were there, how can you not become more faith-filled in the presence of some of those people that are just down on their knees every moment praying to the Lord for the goodness that they have." Andrew affirmed Diane's observations with his own insights:

I was totally blown away by the way the village moved to the beat of Jesus. The Lord was there all the time because they were continually talking to him, and it just flowed through everybody. I don't think it was just because we were there and were going to provide them with something they really wanted. I don't believe that, I think it was an absolute sincerity that they live every single day of their lives.

\section{Discussion}

As we progressed through each day of the trip it was interesting to observe how each participant progressed from general observations, to making comparisons with what they knew from other countries and experiences, to wrestling with deeper insights regarding culture and themselves, to creating new meaning from the new learning. Each participant had her or his own unique learning experiences and revelations that were turning points for them as they considered the implications of their new knowledge (Mezirow, 1991). This new knowledge was evidenced by a shift from each participant's comfort zone, which demonstrated the concept of dispositions - a way of learning to un-know and not-know (Vinz, 1997).

One of the more uncomfortable learning experiences came from the realization that we were the minority wherever we went. Wherever we went in the villages, we were at the center of attention because of our white skin. Children would shout out the word Mzungu, Mzungu (the term for white person) wherever we went, and others would stare. Children would crowd around us, push to get closer, and want to touch our skin or hair. The team members at first felt very uncomfortable with the constant attention. However, after a few days, they realized this was a part of integrating into another culture, and most became more at ease with the attention and even would allow the children to touch their skin or play with their hair. This interaction was an important learning experience for the team members and the children of the village. The importance of the children's learning was particularly evident one afternoon following a session with the girls. The class leader for the eighth graders stood up to give a vote of thanks for the small gifts we had brought, and for our work in their village. As she stated:

We had only seen Mzungus from afar; we had no idea what they were like. Now we know they are human like us. And they have come from abroad to reach this school in this village. Isn't that amazing? 
This moment was quite powerful as we realized how our interactions and visit to the village were also impacting the children in ways we did not expect.

Julie's insight about what to call the Kenyan's was another key learning experience not only for her, but for the entire group. In our conversation with our Kenyan driver, Julie realized that Kenyans were not African American, and that she had been lumping all black people into the same grouping as long as she could remember. This example demonstrated a disconnection regarding the limitations Americans often place on identifications of different populations. We tend to push people into certain groupings when they may identify differently than what the options are listed on a form to indicate one's race. Not only was this conversation uncomfortable for Julie, but also for the rest of the team as they could not believe the question she had asked our driver. However, this particular insight also demonstrated to the rest of the group that we all are in different places with our understanding of cultural issues, and each of us needs to continually examine our own biases and assumptions.

Another interesting aspect of this immersion experience was that these participants were not only navigating a foreign culture, but they were also navigating the culture of learning about each other and how to work with one another while immersed in another culture. Overall, the group bonded well together in this foreign setting, except for a few minor conflicts in personalities and teaching philosophies. Early on in our planning sessions, it was evident that Julie and Gloria had differing views on how to teach the reading and writing lesson portion of our workshop. Before we left on the trip, we had our outlines in place and then planned to refine the lessons once we arrived on site to the village. However, it was evident in the last planning that there would not be a resolution to the philosophical differences between these two women. As team leader and their course instructor, I made the decision to separate the lessons and have each one in charge of their own section. They agreed with the plan and they chose to work out the rest of their differences for the sake of the group and their own learning experiences. At the conclusion of the workshops, it was evident that the separate teaching sessions were very well received by the Kenyan participants, and both women learned a valuable lesson about collaboration.

One of the unanticipated surprises for the group was the spiritual impact of the trip. Our team had a unique opportunity to carry out our work in a school and community setting that practiced Christian concepts on a daily basis, in addition to staying with families who also practiced Christian principles. Even though we represented a Christian university, all participants identified as Christian, and we had prepared for the spiritual 
component in Kenyan, the spiritual lessons were unexpected and profound for each member. As Andrew noted about his spiritual experience:

Wow, I really fell in love with the Kenyan people. They are exceptionally grateful people, appreciative people, and there is so much of their culture that is based around respecting the Lord and being attentive to making sure that they are praising God. And so, I was even more deeply moved than I was expecting.

While I as team leader had been anticipating different responses in the category of biases and assumptions, the major learning in the area of assumptions came from the revelation that the Kenyans did not have as much access to western influences as the team members believed prior to the trip. Even though we had discussed these types of general assumptions related to culture ahead of time in our pre-trip planning sessions, it was evident that the immersion experience was the catalyst in shifting those assumptions for the team members. This topic was mentioned again in the post-trip interviews six months after the trip, as Andrew specifically noted:

When Levi, who is a geography teacher in the community of Ndalu, continued to say that he had never seen a picture of the Grand Canyon, had never even seen a picture of these important landmarks, I was kind of shocked that he did not have access to pictures of these [resources] and dreamed about seeing some of these pictures for years. It just really struck me as how simple it is to access a picture. It is so inaccessible to some parts of the world.

The participants realized they had taken for granted the types of resources they had access to at any given time, and expected the Kenyans to have the same. Even though the majority of Kenyans have cell phones, the primary use is for communication, news, or banking, instead of searching for professional resources. As Christie et al. (2015) noted, these American educators clearly articulated their previously held assumptions framed with their own worldviews. More importantly, as they were faced with knowledge that challenged their previous assumptions, all chose to shift their thinking and move to a new way of knowing (Vinz, 1997).

\section{Application to practice}

One of the major goals of the trip was for each participant to be able to make application to practice from their experiences in Kenya, and each participant shared different applications to their professional practice. For Andrew, he decided he wanted to include more celebrations within his classroom. He was impressed with the Kenyan way of singing and dancing and incorporating small celebrations into the teaching sessions. He believed that celebrating even small events in his classroom would reduce the stress level of his students with regards to the testing and other stressful situations from home and at school. 
Gloria's main application to practice was a spiritual connection. She was raised with a faith background, but her experience in the Kenyan villages both strengthened and deepened her Christian faith. She desired to use her new spiritual insights to further guide her teaching and interactions with her students in America. She concluded a journal entry by stating:

My other 'ah-ha' is that my life is not as much in my control as I thought it was. God is in way more in control and I have to respond, but that's how it's feeling right now. It's a good realization.

Diane wanted to use her new insights to further develop the training for nursing students at our university. She believed that an international component for her students would strengthen their practices no matter where they were. She stated in a debrief session:

I am on fire about bringing nursing students over and having them really embrace these experiences and develop at least a beginning level of not only cultural competency where you know about cultures, but that really deep humility where you ... [realize] 'I'm a child of God, you're a child of God, we're in this together, as an image of God. Let's figure out how we can do this together.' Very egalitarian, no power involved. And I think in the nursing profession, that's been so close to the paternalistic medical profession, which is a power model, to analyze the white versus Kenyan power structure... I think that's really important for students to take a look at.

Julie's desire was to use her big 'ah-ha' of cultural terminologies to accurately call people who they really are. She planned to use this newfound insight within her urban school district, which represented over 90 different languages alone. This trip also allowed Julie the time and space to consider how she wanted to move forward in her professional career. Prior to the trip she had been at a crossroads for how to proceed with her own professional development, but by the end of the trip she had made some key decisions about her professional development that would positively impact her teaching career.

\section{Conclusion}

Each of the participants on this trip to Kenya was an experienced teacher with a variety of experiences, and three of the participants were enrolled in a graduate degree program. All four chose to participate in this cross-cultural teaching and learning opportunity. Furthermore, these teachers were committed to expanding their own knowledge and experiences regarding cross-cultural work in order to benefit their own students. As noted previously, each one of these educators believed prior to the trip they were culturally competent and sensitive and adaptable to any situation. Even though each participant reported various levels of experience with other 
cultures, those prior experiences were foundational to a deeper learning of cultural interactions and how to navigate through those interactions. The more we were immersed into the Kenyan culture, the more that these teachers recognized their own shortcomings regarding all aspects related to cultural influences. As a result, the cultural learning experiences of these educators became much more meaningful and insightful. As Slimbach (2010) notes in research regarding international initiatives, no amount of book knowledge can replace an authentic experience in another culture, whether in the United States or abroad. Since this premise held true with these experienced teachers, then cultural immersion experiences would be even more important for undergraduate teacher education candidates.

The aspects of cultural humility were also evident in the cultural learning experiences of these participants. Throughout the trip they continued to forge relationships with the Kenyans, which is a foundational component to cross-cultural work (Hockett et al., 2013). Furthermore, they listened well and asked questions to clarify information and situations. Even when we had some cultural missteps, such as Gloria's example of speaking against arranged marriages, we engaged in conversations with the Kenyans to correct our assumptions and created healthy dialog that promoted learning for all of us.

It is my recommendation that it is imperative for every institution with a teacher education preparation program to continually examine the ways in which they prepare undergraduate or graduate teachers in the areas of cultural diversity for the classroom. Because of the increase of different international populations in our nation's classrooms, it is vital that teacher education candidates of all levels are prepared to meet the diverse needs of all students in their classrooms. It is one thing to know about different cultures, but it is an entirely different skill and ability to be able to respectfully interact with students and families of another culture and plan appropriate curriculum and lessons to meet the needs of each and every child.

Immersion experiences in another culture either locally or globally can provide one avenue for both teachers and teacher candidates to explore their knowledge and understanding of effective and appropriate cultural interactions and what that learning can mean for their own professional practice. Further, any immersion experience needs to be carefully planned with specific goals related to learning about that culture and how that learning can apply and connect to one's professional practice.

For the teachers in this study, self-reflection was a key component for their cultural learning as they discussed their insights and wrestled with newfound knowledge that demonstrated transformational learning (Mezirow, 1991). Although the preliminary results of this small sample could not be generalized to a larger population, the insights of these 
teachers provide critical information for how we could improve our teaching related to cultures and diversity within our teacher preparation programs. Christian colleges and universities are especially in a unique position to provide leadership in the areas of cultural studies in relation to biblical principles of humility and loving our neighbor. Diane further expanded on her cultural insights after the trip. She had lived in South America for time and thought she had cultural issues all figured out through those prior experiences. Her final journal entry reflected the depth of her cultural insights after the Kenya trip: "I think I have my assumptions covered. But, always, always, there has to be a reflective self-check. Selfreflection is really, really, important."

\section{References}

Berg, B. L. (2012). Qualitative research methods for the social sciences. Boston: Pearson.

Christie, M., Carey, M., Robertson, A., \& Grainger, P. (2015). Putting transformational learning into practice. Australian Journal of Adult Learning, 55(1), 9-30.

Corbett, S., \& Fikkert, B. (2009). When helping hurts: How to alleviate poverty without hurting the poor and yourself. Chicago: Moody Press.

Creswell, J. W. (2013). Qualitative inquiry and research design: Choosing among five approaches (3rd ed.). Los Angeles: Sage.

Creswell, J. W. (2014). Research design: Qualitative, quantitative, and mixed methods approaches. Los Angeles: Sage.

Elmer, D. (2006). Cross-cultural servant hood: Serving the world in Christ like humility. Downers Grove, IL: InterVarsity Press.

Fadiman, A. (1997). The spirit catches you and you fall down. New York: Farrar, Straus and Giroux.

Hockett, E. \& Muhanji, J. (2017). Lessons from cross-cultural collaboration in Kenya: How the principles of cultural humility informed and shaped the work of an American and a Kenyan. Eugene, OR: Wipf \& Stock Publishers.

Hockett, E., Samek, L., \& Headley, S. (2013). Cultural humility: A framework for local and global engagement. ICCTE Journal, (8) 1. Retrieved from http://www.icctejournal.org

Knowles, M. S., Holton, III, E. F., \& Swanson, R. A. (1998). The adult learner (5th ed.). Woburn, MA: Butterworth-Heinemann.

Larrivee, B. (2000). Transforming teaching practice: Becoming the critically reflective teacher. Reflective Practice, 1(3), 293-306.

Leech, N. L., \& Onwuegbuzie, A. J. (2008). Qualitative data analysis: A compendium of techniques and a framework for selection for school psychology research and beyond. School Psychology Quarterly, 23(4), 587-604. doi:10.1037/1045-3830.23.4.587

Marmon, E. L. (2013). Transformational learning theory: Connections within adult Christian education. Christian Education Journal: Research on Educational Ministry, 10(2), 424-431.

Mezirow, J. (1991). Transformative dimensions of adult learning. San Francisco: Jossey-Bass.

Mezirow, J. (1997). Transformational learning: Theory to practice. New Directions for Adult and Continuing Education, 1997(74), 5-12. 
Mezirow, J. (2012). Learning to think like an adult: Core concepts of transformation theory. In E. W. Taylor \& P. Cranton (Eds.), The handbook of transformative learning. San Francisco: Jossey-Bass.

Nwosu, P. O. (2009). The interculturally competent global leader. In D. K. Deardorff. The Sage handbook of intercultural competence. Thousand Oaks, CA: Sage.

Osterman, K. F., \& Kottman, R. B. (1993). Reflective practice for educators. Newbury Park, CA: Corwin Press.

Pusch, M. D. (2009). The interculturally competent global leader. In D. K. Deardorff. The Sage handbook of intercultural competence. Thousand Oaks, CA: Sage.

Ross, L. (2010). Notes from the field: Learning cultural humility through critical incidents and central challenges in community-based participatory research. Journal of Community Practice, 18(2-3), 315-335.

Slimbach, R. (2010). Becoming world wise: A guide to global learning. Sterling, VA: Stylus Publishing.

Tangney, J. P. (2000). Humility: Theoretical perspectives, empirical findings and directions for future research. Journal of Social and Clinical Psychology, 19(1), 70-82.

Taylor, E. W. (2009). Fostering transformative learning. In J. Mezirow \& E. W. Taylor (Eds.), Transformative learning in practice. San Francisco: Jossey-Bass.

Tervalon, M., \& Murray-Garcia, J. (1998). Cultural humility versus cultural competence: A critical distinction in defining physician training outcomes in multicultural education. Journal of Health Care for the Poor and Underserved, 9(2), 117-125.

Thurow, R. (2012). The last hunger season. Philadelphia, PA: Perseus Books.

Vinz, R. (1997). Capturing a moving form: 'Becoming' as teachers. English Education, 29(2), 137-146.

Wear, D. (2008). On outcomes and humility. Academic Medicine, 83(7), 625-626.

Eloise Hockett teaches in both undergraduate and graduate programs at George Fox University and serves on a variety of committees. Eloise is a frequent traveler to Kenya, where she helped develop a peace curriculum for the Quaker secondary schools, assists with professional development in Quaker schools, and promotes education efforts for girls and women in rural areas. Eloise's research interests include adult teaching and learning strategies, peace education, cross-cultural teaching and learning, and cultural humility. 